\title{
Rancang Bangun Sistem Pendeteksian Dini Tanah Longsor Berbasis SMS
}

\author{
Gita Okta Diana*, Wildian \\ Jurusan Fisika FMIPA Universitas Andalas, Padang \\ Kampus Unand Limau Manis, Pauh Padang 25163 \\ *dianagitaokta@gmail.com
}

\begin{abstract}
ABSTRAK
Suatu sistem peringatan dini tanah longsor berbasis SMS telah dirancang-bangun untuk mendeteksi dan menginformasikan kepada masyarakat lokasi tanah longsor. Metode yang digunakan adalah metode penginderaan berat dengan sistem sensor terdiri dari sensor jarak VL53L00X (objek pantul berupa cermin) dan pegas (dengan panjang $9 \mathrm{~cm}$, diameter $2 \mathrm{~cm}$ dan konstanta pegas $62,39 \mathrm{~N} / \mathrm{m}$ ). Ketika terjadi pergeseran tanah dalam arah bidang gelinciran, ujung atas pegas akan tertekan oleh gaya berat bidang tanah yang bergeser sehingga jarak objek pantul dengan sensor semakin dekat. Akibatnya, jarak yang dideteksi sensor semakin besar. Hasil uji menunjukkan bahwa prototype mampu mendeteksi pergeseran tanah permukaan dalam rentang 1 hingga $7 \mathrm{~cm}$. Selain itu, sistem ini juga mampu mengirim SMS untuk status siaga II (pergeseran tanah sebesar 2,39 cm), siaga III $(3,17 \mathrm{~cm})$, dan bahaya $(4,11 \mathrm{~cm}$; bunyi alarm).

Kata kunci : sistem peringatan dini, tanah longsor, sensor jarak VL53L0X, pegas, SMS
\end{abstract}

\section{ABSTRACT}

SMS-based landslide early warning system has been designed to detect and inform the residents of landslide area using weight sensing method. The sensor system consists of a VL53LOX proximity sensor (a mirror as reflecting object) and a spring (9 cm long, the diameter of $2 \mathrm{~cm}$, and the spring constant of $62.39 \mathrm{~N} / \mathrm{m}$ ). The sensor system is installed at the base of the slope. When a ground move in the direction of the slip plane, the upper of the spring will be depressed by the gravity of moving ground, so distance of the reflected object with the sensor is closer. The result show that the prototype system is able to detect surface soil shifts in the range of $1 \mathrm{~cm}$ to $7 \mathrm{~cm}$. In addition, this system is also able to send SMS for standby I (land of $2.39 \mathrm{~cm})$, standby II $(3.17 \mathrm{~cm})$, and danger $(4.11 \mathrm{~cm}$; alarm sound) status.

Keywords: early warning system, landslide, VL53LOX proximity sensor, spring, SMS

\section{PENDAHULUAN}

Sumatera Barat termasuk daerah rawan bencana alam seperti gempa, tsunami, banjir, tanah longsor, dan gunung meletus, yang dapat menyebabkan kerusakan lingkungan, kerugian harta benda, dampak psikologis, serta korban jiwa. Bencana alam yang paling sering terjadi di provinsi ini dalam rentang 2008-2012 adalah banjir dan tanah longsor (UN-OCHA, 2014). Hampir semua wilayah (19 kabupaten/kota) di Sumatera Barat berpotensi mengalami gerakan tanah/ longsor, dengan tingkatan potensi umumnya menengah hingga tinggi. Daerah-daerah di kota Padang yang berpotensi mengalami gerakan tanah/ longsor adalah Bungus Teluk Kabung, Pauh, Padang Barat, Padang Timur, Padang Selatan, Lubuk Begalung, Lubuk Kilangan, Kuranji, dan Koto Tengah (Kemen-ESDM, 2017). Untuk mengurangi dampak bencana longsor, perlu adanya pencegahan berupa penanaman pohon di lahan tandus dan pendeteksian dini tanah longsor.

Priyanto dkk. (2015) telah merancang sistem monitoring pergeseran tanah dengan menggunakan sensor Linier Variable Differential Transformer (LVDT). LVDT dilengkapi dengan potensiometer untuk mengetahui titik mana yang mengalami pergeseran. Data pergeseran yang didapat akan dikirimkan dari lapangan menuju user (pemantau) menggunakan komunikasi telemetri via Global System for Mobile communication (GSM) yang ditampilkan dalam sebuah aplikasi sistem monitoring. Sistem juga berfungsi sebagai early warning yaitu aktifnya sirine peringatan ketika pergeseran telah mencapai kondisi bahaya longsor. Hasil dari pengujian alat terdapat dua kali percobaan yang gagal akibat keterbatasan potensiometer dalam mendeteksi pergeseran.

Pergeseran tanah juga dapat dideteksi dengan sensor berat yang terdiri dari pegas, LED dan fotodioda (Mardhatillah, 2017). Sebuah LED (Light Emiting Diode) dilekatkan ke salah satu ujung pegas dan sebuah fotodioda pada ujung lainnya. Jarak LED dan fotodioda akan 
memendek saat terjadi pergeseran tanah. Indikator LED akan aktif ketika sistem mendeteksi pergeseran tanah dalam rentang $1 \mathrm{~cm}$ hingga $3 \mathrm{~cm}$ dengan status siaga, sedangkan pada pergeseran besar dari $4 \mathrm{~cm}$ berstatus bahaya.

Berdasarkan penelitian di atas, maka pada penelitian ini telah dikembangkan sebuah sistem peringatan dini yang mampu mengirimkan informasi peringatan tanah longsor ke masyarakat umum menggunakan sistem komunikasi jarak jauh berbasis SMS. SMS yang dikirim yaitu peringatan tanah longsor dengan kondisi siaga II dan siaga III serta link location dari lokasi tanah longsor, sehingga informasi peringatan lebih cepat diketahui oleh masyarakat umum. Link location diakses pada Google Map untuk menunjukkan rute terdekat menuju lokasi longsor, sehingga masyarakat bisa menghindari rute tersebut untuk dilewati agar terhindar dari bencana. Sistem juga dilengkapi alarm sebagai peringatan ketika pergeseran telah mencapai kondisi bahaya longsor. Sistem yang telah dirancang mampu mendeteksi pergeseran tanah menggunakan sensor jarak VL53L0X, serta mengirimkan informasi peringatan melalui SMS dengan menggunakan modul SIM800L.

\section{METODE}

\subsection{Perancangan Diagram Blok Sistem}

Diagram blok sistem terdiri dari blok rangkaian sensor pergeseran tanah (terdiri dari sensor jarak VL53L0X yang dipasang bersamaan dengan pegas) untuk mengontrol pergeseran tanah, blok Modul SIM800L (terdiri dari Sim Card) sebagai tranceiver, blok board Arduino UNO R3 untuk mengontrol sistem rangkaian, blok SMS dan blok buzzer sebagai peringatan akan terjadinya longsor. Saat pergeseran tanah $>2 \mathrm{~cm}$ dan $<2,9 \mathrm{~cm}$ maka sistem akan mengirim SMS "Siaga II", beserta link location, pada pergeseran $>3 \mathrm{~cm}$ dan $<4 \mathrm{~cm}$ sistem akan mengirim SMS "Siaga III, beserta link location, sedangkan pergeseran $>4 \mathrm{~cm}$ sistem akan mengaktifkan buzzer sebagai alarm. Link location yang dikirim dapat diakses pada Google Map serta jarak pergeseran tanah ditampilkan melalui LCD 2 x 16. Diagram blok sistem ditunjukkan pada Gambar 1.

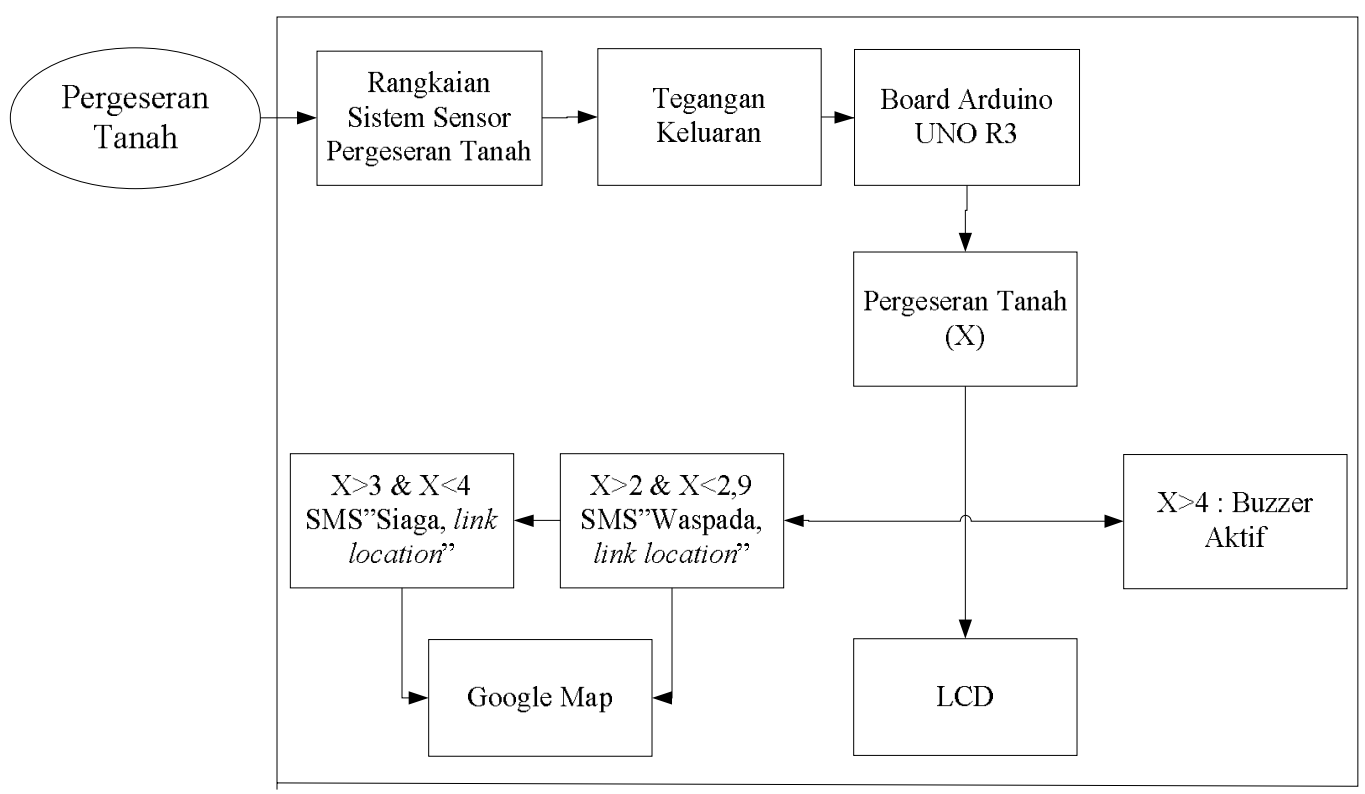

Gambar 1. Diagram blok system peringatan dini tanah longsor

\subsection{Diagram Alir Perangkat Lunak Sistem}

Perancangan program menggunakan software Arduino IDE untuk menjalankan perintah yang telah diprogram. Program yang akan ditulis diawali dengan inisialisasi pin mikrokontroler. Program dibuat sesuai dengan port yang telah ditentukan sebelumnya sebagai masukan dan keluaran. Port A3 sebagai port masukan dari sistem sensor, sedangkan untuk port keluaran menggunakan port digital sebagai keluaran berupa tampilan pergeseran tanah pada LCD, buzzer dan link location dalam bentuk SMS pada Smartphone.Sebelum dilakukan perancangan 
program pada PC maka perancangan program terlebih dahulu dibuat dalam sebuah diagram alir yang akan menjadikan alur pemikiran untuk pembuatan program. Diagram alir ditunjukkan pada Gambar 2.

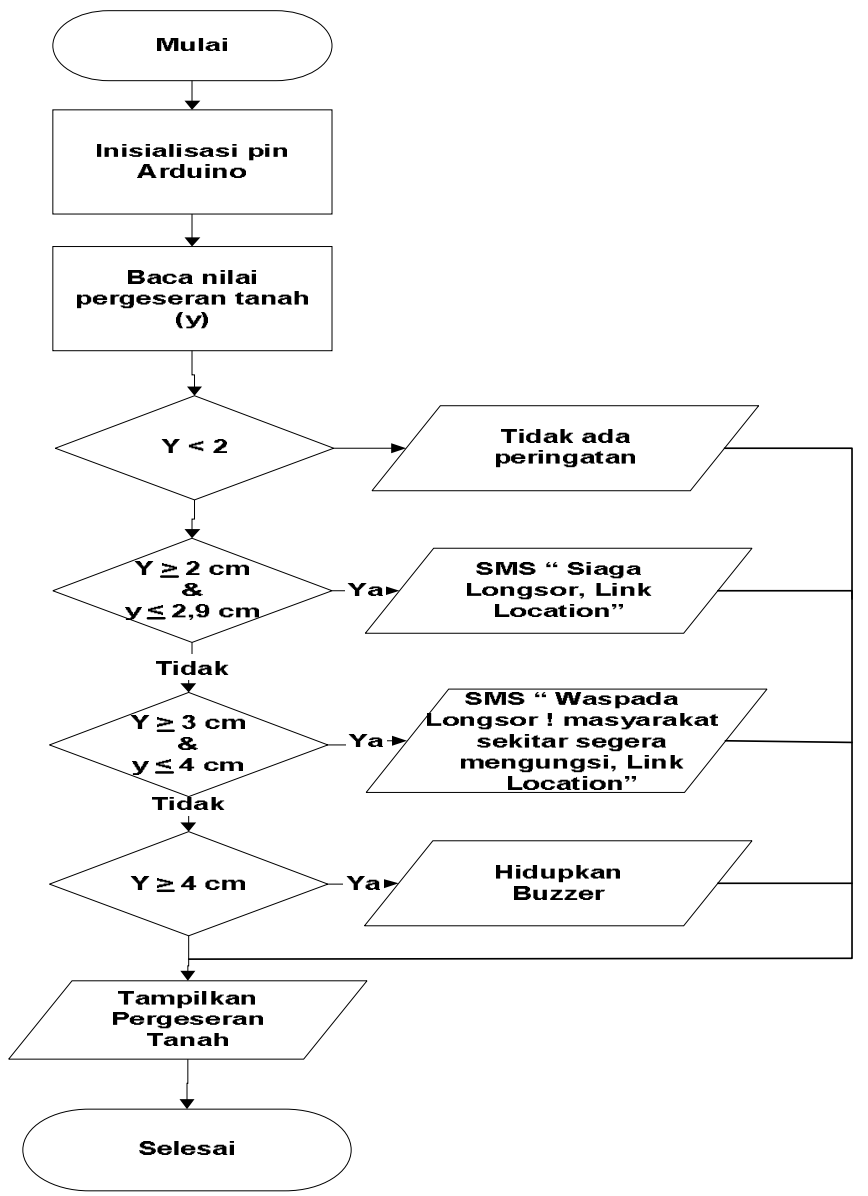

Gambar 2. Diagram alir program

\subsection{Perancangan Bentuk Prototipe Sistem Pendeteksian Dini Tanah Longsor}

Perancangan bentuk prototipe dimulai dari perancangan bentuk fisik alat yang mendeteksi pergeseran tanah. Gambar dari alat pendeteksi tanah longsor ditunjukkan pada Gambar 3.Sistem sensor berada didalam pipa yang memiliki ukuran diameter yang lebih besar. Alat tersebut akan diuji secara keseluruhan yang ditunjukkan pada Gambar 3.

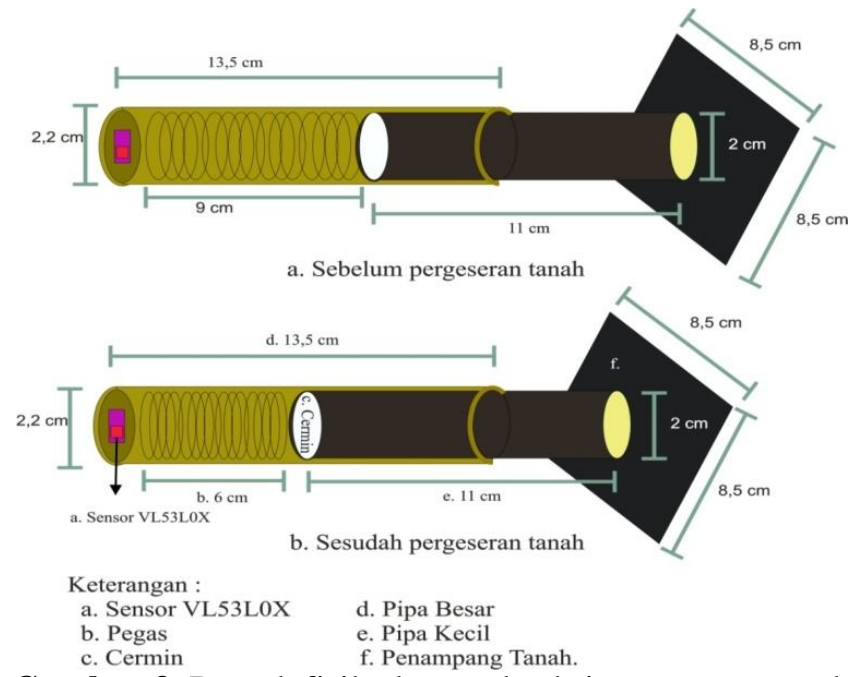

Gambar 3. Bentuk fisik alat pendeteksi pergeseran tanah 


\section{HASIL DAN DISKUSI}

\subsection{Hasil Karakterisasi Sensor Pergeseran Tanah}

Karakterisasi sensor pergeseran tanah dilakukan agar mengetahui jarak pergeseran tanah dengan memberikan variasi berat yang berbeda pada pegas. Saat berat menekan sistem sensor, maka jarak pergeseran tanah yang dideteksi sensor semakin besar. Pegas yang digunakan pada sistem sensor memiliki panjang $9 \mathrm{~cm}$, maka jarak pergeseran tanah yang digunakan berkisar antara $1 \mathrm{~cm}$ sampai dengan $8 \mathrm{~cm}$. Hasil variasi berat terhadap jarak pergeseran ditunjukkan pada Tabel 1.

Tabel 1. Variasi Berat terhadap Pergeseran Tanah.

\begin{tabular}{ccc}
\hline $\begin{array}{c}\text { Massa } \\
(\text { gram })\end{array}$ & $\begin{array}{c}\text { Gaya } \\
\text { Berat } \\
(\mathbf{N})\end{array}$ & $\begin{array}{c}\text { Jarak } \\
\text { Pergeseran } \\
(\mathbf{c m})\end{array}$ \\
\hline 150 & 1,5 & 1,02 \\
200 & 2,0 & 1,34 \\
250 & 2,5 & 1,49 \\
300 & 3,0 & 1,85 \\
350 & 3,5 & 2,25 \\
400 & 4,0 & 2,47 \\
450 & 4,5 & 2,70 \\
500 & 5,0 & 310 \\
550 & 5,5 & 3,49 \\
600 & 6,0 & 370 \\
650 & 6,5 & 4,15 \\
700 & 7,0 & 4,55 \\
750 & 7,5 & 4,79 \\
800 & 8,0 & 4,89 \\
850 & 8,5 & 5,19 \\
900 & 9,0 & 5,55 \\
950 & 9,5 & 5,86 \\
1000 & 10,0 & 6,15 \\
1050 & 10,5 & 6,64 \\
1100 & 11,0 & 7,05 \\
\hline
\end{tabular}

Variasi berat yang diberikan akan menyebabkan perubahan panjang pada pegas. Perubahan panjang pegas akan dijadikan sebagai nilai pergeseran tanah yang akan diprogram pada Arduino Uno R3. Hasil karakterisasi sensor pergeseran tanah menunjukkan bahwa jarak pergeseran tanah yang dihasilkan sensor berbanding lurus dengan variasi gaya berat. Data pengukuran dari Tabel 4.2 dapat diplot dalam bentuk grafik jarak pergeseran terhadap gaya berat seperti pada Gambar 4.

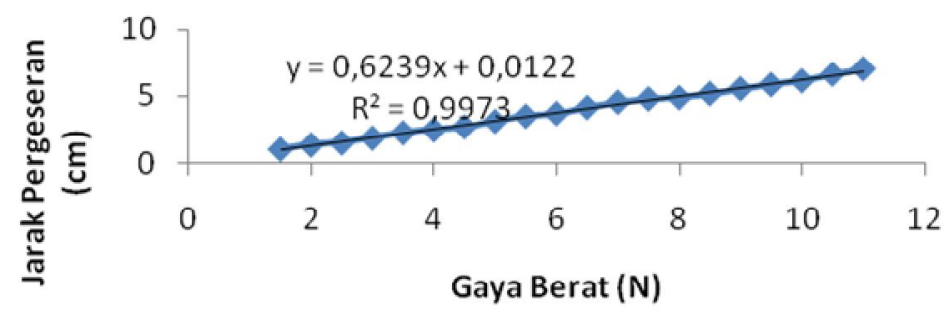

Gambar 4. Grafik hubungan jarak keluaran sensor dengan gaya berat.

Gambar 4. memperlihatkan bahwa gaya berat berbanding lurus dengan jarak pergeseran tanah dengan koefisien korelasi $R^{2}=0,9973$ yang bersifat linear. Berdasarkan fungsi transfer $y$ $=.0,6239 x+0,0122$ diperoleh konstanta pegas sebesar $0,6239 \mathrm{~N} / \mathrm{cm}$ dengan arti tiap bertambahnya gaya berat sebesar $0,6239 \mathrm{~N} / \mathrm{cm}$ mengakibatkan bertambahnya pergeseran pegas 
sebesar $1 \mathrm{~cm}$. Nilai 0,0122 merupakan nilai offset yang menyatakan nilai awal dari sensor pada saat gaya berat bernilai nol.

\subsection{Hasil Pengujian SIM800L}

Pengujian dilakukan dengan menghitung waktu respon Arduino sejak pesan dikirimkan hingga pesan diterima oleh pengguna. Pengujian waktu pengiriman SMS sampai SMS diterima dilakukan dengan jarak yang berbeda. Pengujian dilakukan dengan memvariasikan jarak antara pengirim dan penerima yaitu $0,55 \mathrm{~km}, 10 \mathrm{~km}$ dan $20 \mathrm{~km}$. Rata-rata waktu respon dari delapan kali percobaan dapat dilihat pada Tabel 2.

Tabel 2. Variasi Jarak Terhadap Waktu Pengiriman SMS sampai SMS diterima

\begin{tabular}{cc}
\hline $\begin{array}{c}\text { Jarak } \\
(\mathbf{m})\end{array}$ & $\begin{array}{c}\text { Rata-rata Waktu Pengiriman SMS } \\
\text { sampai SMS diterima (detik) }\end{array}$ \\
\hline 550 & 10,399 \\
10000 & 13,009 \\
20000 & 16,445 \\
\hline
\end{tabular}

Dari ke tiga data yang didapatkan, terlihat jarak mempengaruhi waktu pengiriman SMS sampai SMS diterima oleh pengguna. Jarak dan waktu berbanding lurus. Semakin jauh jarak pengguna dengan sistem, waktu yang dibutuhkan juga bertambah.

\subsection{Pengujian Besar Sudut terhadap Pergeseran Tanah}

Pengujian besar sudut lereng dilakukan untuk melihat besar pergeseran tanah yang terjadi dengan sudut lereng yang berbeda. Hal ini dilakukan untuk membuktikan bahwa salah satu penyebab tanah longsor adalah kemiringan lereng.

Tabel 3. Pengaruh besar sudut terhadap pergeseran tanah

\begin{tabular}{cc}
\hline Besar Sudut $\left({ }^{\circ}\right)$ & $\begin{array}{c}\text { Pergeseran Tanah } \\
(\mathbf{c m})\end{array}$ \\
\hline 30 & 1,15 \\
35 & 1,98 \\
40 & 3,45 \\
45 & 4,11 \\
\hline
\end{tabular}

Tabel 3 menunjukan pengaruh besar sudut lereng terhadap pergeseran tanahyang terjadi. Semakin besar sudut lereng maka pergeseran tanah akan semakin besar.Hal ini dikarenakan semakin curam suatu lereng maka berat tanah yang dipengaruhi oleh besarnya sudut kemiringan menyebabkan semakin besarnya percepatan gerak tanah, sehingga pergeseran tanah yang dihasilkan juga semakin besar.

\subsection{Pengujian Rancang Alat Secara Keseluruhan}

Pengujian terhadap sistem peringatan dini tanah longsor berbasis SMS menggunakan simulasi tanah longsor buatan. Status pergeseran tanah telah dideteksi dengan baik oleh sistem sensor dengan status siaga I, siagaII, siaga III dan bahaya. Setiap level pergeseran tanah akan memberikan peringatan berupa SMS dan hidupnya buzzer saat pergeseran tanah berada pada level bahaya. Penentuan siaga dengan pergeseran tanah tertentu berbeda pada setiap lereng. Setiap lereng memiliki stabilitas yang berbeda dan kondisi tanah yang berbeda sehingga pergeseran tanah yang terjadi pada setiap lereng juga akan berbeda. Status siaga dengan pergeseran tanah (x) dibuat mendekati penelitian Mardhatillah pada tahun 2017 dengan status siaga I $(1 \leq x<2)$, siaga II $(2 \leq x<3)$, siaga III $(3 \leq x<4)$, dan bahaya $(x \geq 4)$. Data pengujian secara keseluruhan dapat dilihat pada Tabel 4. 
Tabel 4. Pengaruh besar sudut terhadap pergeseran tanah

\begin{tabular}{ccc}
\hline $\begin{array}{c}\text { Pergeseran Tanah } \\
(\mathbf{c m})\end{array}$ & $\begin{array}{c}\text { Status } \\
\text { Peringatan }\end{array}$ & Alarm \\
\hline 1,12 & Siaga I & - \\
2,39 & Siaga II & SMS (Link Location) \\
3,17 & Siaga III & SMS (Link Location, masyarakat segera mengungsi) \\
4,11 & Bahaya & Buzzer \\
\hline
\end{tabular}

\section{KESIMPULAN}

Berdasarkan data dan analisis serta pengujian hasil keseluruhan rancang bangun sistem deteksi dini tanah longsor berbasis SMS menggunakan metode penginderaan berat yang telah dirancang, dapat bekerja seperti yang telah direncanakan dan berjalan sesuai dengan yang diinginkan. Pembacaan besar pergeseran tanah yang ditampilkan pada layar LCD 16x2 dan sistem alarm (SMS dan buzzer) diproses menggunakan Arduino Uno R3. Sistem peringatan dini tanah longsor mampu mengirimkan informasi lokasi tanah longsor menggunakan layanan SMS saat status siaga I (pergeseran tanah sebesar $1,12 \mathrm{~cm}$ ), siaga II $(2,39 \mathrm{~cm})$, dan siaga III $(3,17 \mathrm{~cm})$, serta buzzer akan hidup saat status bahaya (pergeseran tanah sebesar 4,11 cm).

\section{DAFTAR PUSTAKA}

Priyanto, Subagiyo, H. dan Madona, P.,"Rancang Bangun Peringatan Bahaya Longsor dan Monitoring Pergeseran Tanah Menggunakan Komunikasi Berbasis GSM", Jurnal Elementer, Vol. 1, No. 2, Politeknik Caltex Riau, 2015

Mardhatillah, E.,"Rancang bangun system peringatan dini tanah longsor berbasis mikrokontroler ATmega328 menggunakan metode Penginderaan berat", Skripsi SI, Univeritas Andalas, 2017

Kemen-ESDM, Wilayah Potensi Gerakan Tanah di Provinsi Sumatera Barat,2017, diakses September 2017.

UN-OCHA. 2014. Indonesia: Province Infographic-West Sumatra, 2014, diakses Maret 2018 